Jurnal Visionida, Volume 4 Nomor 1 Juni 2018

\title{
PENGARUH BUDAYA KERJA DAN IKLIM KERJA TERHADAP DISIPLIN KERJA PEGAWAI KANTOR PERTANAHAN KOTA BOGOR
}

\section{THE EFFECT OF WORK CULTURE AND WORK CLIMATE ON EMPLOYEE WORK DISCIPLINE IN KANTOR PERTANAHAN KOTA BOGOR}

\author{
Gita Puspita $^{1)}$; Sudarijati ${ }^{2}$ \\ Program Studi Manajemen, Fakultas Ekonomi, Universitas Djuanda Bogor \\ Email : gipusgita@unida.ac.id
}

\begin{abstract}
This study aims to determine the effect of work culture and work climate on employee work discipline in Kantor Pertanahan Kota Bogor. The research was conducted using qualitative and quantitative approaches. Verifikatif form of research, tested the validity, reliability test and classical assumptions. Multiple linear regression analysis. Data were collected through questionnaires, observations, and interviews. The method of analysis using descriptive analysis, multiple regression analysis, correlation analysis, coefficient of determination, $F$ test and $t$ test. Eighty employees were taken as samples. The results showed the average of employee responses to strong employee work culture. Employee response to the average work climate is good. Employee response to high average work discipline. Simultaneously work culture and work climate have positive and significant influence to work discipline. Partially indicate that work culture and work climate have positive and significant effect to work discipline.
\end{abstract}

Keywords : work culture, work climate, and work discipline.

\begin{abstract}
ABSTRAK
Penelitian ini bertujuan untuk mengetahui pengaruh budaya kerja dan iklim kerja terhadap disiplin kerja pegawai Kantor Pertanahan Kota Bogor. Penelitian dilakukan melalui pendekatan secara kualitatif dan kuantitatif. Bentuk penelitian adalah verifikatif meliputi uji validitas, uji reliabilitas dan asumsi klasik analisis regresi linier berganda. Data dikumpulkan melalui kuesioner, observasi, dan wawancara. Metode analisis menggunakan analisis deskriptif, analisis regresi berganda, analisis korelasi, koefisien determinasi, uji F dan uji t. Delapan puluh pegawai diambil sebagai sampel. Hasil penelitian menunjukkan rata-rata tanggapan pegawai terhadap budaya kerja pegawai kuat. Tanggapan pegawai terhadap iklim kerja rata-rata adalah baik. Tanggapan pegawai terhadap disiplin kerja rata-rata tinggi. Secara simultan budaya kerja dan iklim kerja berpengaruh positif dan signifikan terhadap disiplin kerja. Secara parsial menunjukkan bahwa budaya kerja dan iklim kerja berpengaruh positif dan signifikan terhadap disiplin kerja.
\end{abstract}

Kata Kunci : Budaya kerja, iklim kerja, dan disiplin kerja. 


\section{PENDAHULUAN}

Kedisiplinan sebagai sebuah ukuran untuk mengetahui baik buruknya peranan seorang pemimpin. Selain itu, disiplin diartikan sebagai bentuk kepatuhan pegawai dan konsistensi yang memperlihatkan seberapa besar tim mampu bekerja dalam organisasi. Disiplin kerja juga sebagai sebuah proses berperilaku pada peraturan yang ditetapkan perusahaan, baik yang ditulis maupun tidak ditulis serta tidak mengelak dalam menerima sanksi (Mills \& Merrylin, 2007). Dalam upaya meningkatkan produktivitas kerja dibutuhkan kesadaran tentang pentingnya disiplin masyarakat yang akan berpengaruh positif bagi pemeliharaan disiplin kerja (Siswanto, 2012). Disiplin kerja sebagai tuntutan bagi instansi dalam melayani masyarakat yang menggunakan jasanya. Pegawai diwajibkan menaati peraturan untuk meraih tujuan sesuai ketentuan. Pegawai yang tidak disiplin akan berdampak terhadap suatu pekerjaan yang tidak terselesaikan dan mempengaruhi rendahnya pelayanan terhadap masyarakat hal ini menyebabkan tidak optimal kinerja instansi tersebut. Menurut Erawati (2007) mengemukakan bahwa budaya kerja, kepemimpinan, dan kompensasi berpengaruh terhadap disiplin kerja pegawai. Menurut (Wirawan, 2007) memaparkan bahwa iklim kerja berpengaruh terhadap disiplin kerja pegawai.

Keberhasilan sebuah pekerjaan, berasal dari nilai-nilai dan tingkah laku yang melekat dalam kebiasaan dikenal sebagai budaya. Budaya dihubungkan dengan mutu kerja yang disebut budaya kerja. Budaya kerja sudah dikenal manusia, namun tidak seketika langsung disadari oleh manusia bahwa keberhasilan sebuah pekerjaan berasal dari nilai-nilai dan perilaku kebiasaannya (Supriyadi \& Guno, 2006). Tujuan dari Budaya kerja untuk memperbaiki perilaku SDM agar produktivitas kerja meningkat serta mampu menghadapi kendala di masa depan (Fernandez, 2006).

Selain budaya kerja, iklim kerja juga berperan dalam penegakan disiplin kerja pegawai. Iklim kerja sebagai kondisi atau wujud dari budaya yang diciptakan. Ketika iklim kerja tidak mendukung berakibat pada tujuan perusahaan akan sulit direalisasikan. Menurut (Kusdi, 2011) iklim kerja adalah sebagai persepsi tentang kebijakan, praktekpraktek dan prosedur-prosedur organisasi yang dirasa dan diterima oleh orang-orang di perusahaan ataupun pandangan sesorang terhadap tempat pekerjaan. Iklim kerja dapat berpengaruh terhadap sikap maupun pandangan pekerja, sehingga mendorong pekerja melakukan yang terbaik bagi instansi.

Secara umum peraturan tentang disiplin kerja PNS sudah diberlakukan, namun ketaatan dalam mematuhi peraturan tersebut belum sepenuhnya dilakukan sehingga berakibat kedisiplinan pegawai rendah. Sebagai contoh kelemahan pegawai dalam disiplin kerja, misalnya terlambat masuk kantor, tidak hadir upacara pagi, pulang lebih awal waktu, dan tidak bekerja tanpa keterangan.

BPN merupakan Lembaga Negara Non Kementrian yang bertanggung jawab kepada Presiden dan dipimpin oleh Kepala. Lembaga ini juga yang melakukan tugas pemerintah di bidang pertanahan secara nasional, regional, dan sektoral sesuai dengan aturan yang berlaku di Indonesia.

Pada penelitian di lokasi penelitian terdahulu telah diperoleh oleh penulis ditemukan hasil penelitian tahun 2016 diperoleh informasi bahwa kondisi disiplin kerja PNS cukup rendah. Hal-hal yang menjadi indikator dari data tersebut dapat diidentifikasikan di antaranya adalah kurangnya disiplin kerja yang sering dilakukan oleh PNS pada instansi tersebut. Adapun rekapitulasi absensi PNS Kantor Pertanahan Kota Bogor dapat dicermati langsung pada Tabel 1.1 berikut ini: 
Tabel 1.1 Rekapitulasi Absensi PNS Kantor Pertanahan Kota Bogor Tahun 2016

\begin{tabular}{|c|c|c|c|c|c|c|c|c|c|}
\hline \multirow[t]{2}{*}{ Bulan } & \multirow{2}{*}{$\begin{array}{l}\text { Jumlah } \\
\text { Karyawan } \\
\text { (orang) }\end{array}$} & \multirow{2}{*}{$\begin{array}{l}\text { Jumlah Hari } \\
\text { Kerja } \\
\text { Perbulan per } \\
\text { karyawan } \\
\text { (hari) }\end{array}$} & \multirow{2}{*}{$\begin{array}{l}\text { Total Hari } \\
\text { Kerja } \\
\text { perbulan } \\
\text { (hari) }\end{array}$} & \multicolumn{2}{|c|}{$\begin{array}{c}\text { Jumlah hari kerja tidak } \\
\text { hadir } \\
\text { (Tanpa Keterangan) }\end{array}$} & \multicolumn{2}{|c|}{$\begin{array}{c}\text { Jumlah hari } \\
\text { Keterlambatan Kerja } \\
\text { Karyawan } \\
\end{array}$} & \multicolumn{2}{|c|}{$\begin{array}{l}\text { Jml hari karyawan } \\
\text { Plg Sblm waktunya }\end{array}$} \\
\hline & & & & $\begin{array}{l}\text { Jumlah } \\
\text { (hari) }\end{array}$ & $\%$ & $\begin{array}{l}\text { Jumlah } \\
\text { (hari) }\end{array}$ & $\%$ & $\begin{array}{l}\text { Jumlah } \\
\text { (hari) }\end{array}$ & $\%$ \\
\hline Jan & 94 & 20 & 1880 & 83 & 4.41 & 217 & 11.54 & 117 & 6.22 \\
\hline $\mathrm{Feb}$ & 92 & 20 & 1840 & 91 & 4.95 & 264 & 14.35 & 114 & 6.20 \\
\hline Mar & 91 & 21 & 1911 & 99 & 5.18 & 217 & 11.36 & 116 & 6.07 \\
\hline Apr & 90 & 21 & 1890 & 103 & 5.45 & 228 & 12.06 & 128 & 6.77 \\
\hline May & 90 & 20 & 1800 & 83 & 4.61 & 222 & 12.33 & 121 & 6.72 \\
\hline Jun & 88 & 22 & 1936 & 79 & 4.08 & 525 & 27.12 & 90 & 4.65 \\
\hline Jul & 88 & 16 & 1408 & 73 & 5.18 & 162 & 11.51 & 145 & 10.30 \\
\hline Aug & 87 & 22 & 1914 & 73 & 3.81 & 227 & 11.86 & 93 & 4.86 \\
\hline Sep & 86 & 21 & 1806 & 52 & 2.88 & 280 & 15.50 & 93 & 5.15 \\
\hline Oct & 86 & 21 & 1806 & 55 & 3.05 & 204 & 11.30 & 108 & 5.98 \\
\hline Nov & 86 & 22 & 1892 & 96 & 5.07 & 292 & 15.43 & 89 & 4.70 \\
\hline Dec & 80 & 20 & 1600 & 106 & 6.63 & 212 & 13.25 & 103 & 6.44 \\
\hline & $\begin{array}{c}\text { Jumlah } \\
\text { Rata-rata }\end{array}$ & & & & 4.61 & & 13.97 & & 6.17 \\
\hline
\end{tabular}

Sumber: Kantor Pertanahan Kota Bogor (Data diolah), 2017

Berdasarkan Tabel 1.1, terlihat bahwa setiap bulan pada tahun 2016 terjadi fluktuasi tingkat kedisplinan kerja PNS. Jumlah PNS yang tidak hadir tanpa keterangan sebesar $4,61 \%$, PNS yang terlambat kerja sebesar $13,97 \%$, dan PNS yang pulang diawal waktu sebesar $6,17 \%$. Dalam hal ini sangat terkait dengan standar kerja dari instansi tersebut yaitu untuk kehadiran karyawan adalah $100 \%$ di luar sakit dan izin dan untuk keterlambatan serta pulang diawal waktu adalah $0 \%$. Disiplin kerja yang rendah, diduga karena budaya kerja belum optimal dan iklim kerja kurang baik.

Berdasarkan observasi awal terdapat beberapa budaya kerja yang terjadi menjadi penyebab kurang lancarnya pelaksanaan tugas

\section{MATERI}

\section{Budaya Kerja}

Menurut Ndraha (2005), budaya kerja diartikan sekumpulan konsep dasar atau sebagai revolusi mental yang berfungsi agar seperti budaya kurang mampu memisahkan jam kerja, jam dinas, dan urusan pribadi, budaya dengan volume pekerjaan yang tinggi dan tanggungjawab kepada PNS yang berprestasi. Akan tetapi sebaliknya, kurang percaya terhadap PNS yang belum berprestasi.

Selain budaya kerja, iklim kerja juga dapat berpengaruh terhadap disiplin kerja pegawai. Selanjutnya, iklim kerja yang tercipta dirasakan kurang kondusif bagi pegawai dalam melakukan pekerjaannya. Hal ini tercermin dari komunikasi antar pegawai tidak berjalan optimal, kurangnya komitmen pegawai terhadap pekerjaan, dan kurangnya dukungan dari pihak atasan/pimpinan terhadap prestasi kerja.

kerja lebih efesien dan hubungan kerja yang individu dalam sekelompok masyarakat. Menurut Ndraha (2005) indikator dari sebuah budaya kerja terdiri dari sebagai berikut: 
a. bersedia menerima arahan atasan

b. Senang menerima tanggungjawab kerja

c. Bekerja sebagai ibadah

d. Mengerjakan sesuai tugasnya

e. Mengatasi kendala kerja

f. Membuat laporan kerja

g. Jujur dalam kerja

h. Kerjasama dengan sesama

i. Mengevaluasi pekerjaan

\section{Iklim Kerja}

Wirawan (2007), iklim kerja sebagai mutu lingkungan yang timbul dari dalam perusahaan dan berlangsung secara terus-menerus, dirasakan oleh karyawan perusahaan sehingga memberikan pengaruh terhadap tingkah laku karyawannya. Indikator iklim kerja terdiri dari standar perusahaan, struktur perusahaan, tanggungjawab perusahaan, Penghargaan, Dukungan, dan Komitmen dari semua SDM di lingkungan perusahaan.

\section{Disiplin Kerja}

Menurut (Rivai, 2011) disiplin kerja sebagai suatu pedoman para pimpinan perusahaan untuk melakukan komunikasi dua agar karyawan bersedia merubah sikap dan berusaha mampu menciptakan kesadaran dari sendiri untuk mematuhi aturan perusahaan.

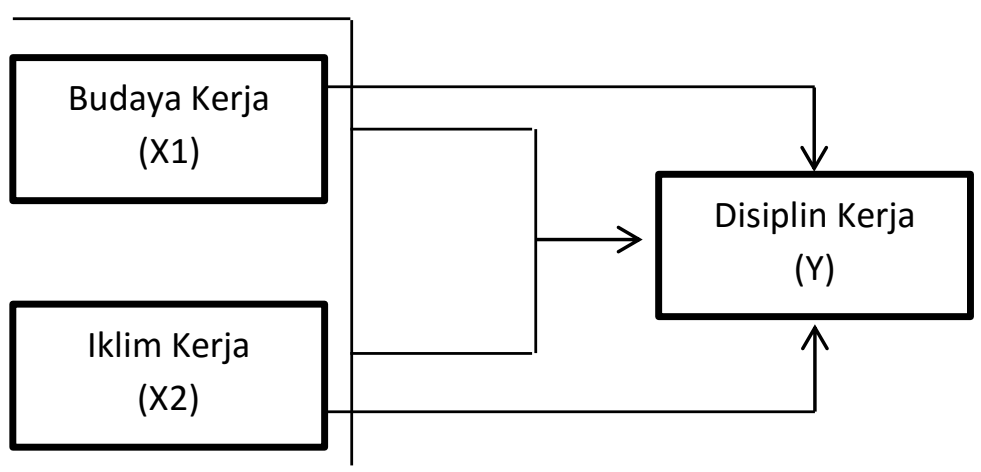

\section{Gambar 1. Kerangka Pemikiran}

\section{Hipotesis Penelitian}

$\mathrm{H}_{1} \quad$ : Budaya kerja dan iklim kerja secara simultan berpengaruh positif dan signifikan terhadap disiplin kerja

$\mathrm{H}_{2} \quad$ : Budaya kerja berpengaruh positif dan signifikan terhadap disiplin kerja

$\mathrm{H}_{3}$ : Iklim kerja berpengaruh positif dan signifikan terhadap disiplin kerja

\section{METODE PENELITIAN}

Penelitian ini digunakan untuk mengetahui pengaruh budaya kerja dan iklim kerja terhadap disiplin kerja. Dalam melakukan penelitian menggunakan bentuk penelitian verifikatif melalui pengumpulan data pada perusahaan. Adapun verifikatif digunakan untuk menguji hipotesis dengan perhitungan statistik (Nazir, 2003). Jenis data primer dengan melakukan wawancara dan menggunakan kuesioner. Objek penelitiannya adalah PNS Kantor Pertanahan Kota Bogor, yang beralamat J1. Achmad Yani No. 41 Bogor Jawa Barat.

\section{Operasional Variabel}

Variabel yang dipakai yaitu budaya kerja $\left(\mathrm{X}_{1}\right)$, iklim kerja $\left(\mathrm{X}_{2}\right)$, serta variabel terikat ialah disiplin kerja (Y). Operasionalisasi variabel terdapat di Tabel berikut ini: 
Tabel 2 Operasional Variabel

\begin{tabular}{|c|c|c|c|c|c|}
\hline No. & Variabel & Konsep Variabel & Indikator & Skala Ukur & $\begin{array}{c}\text { Item } \\
\text { pertanyaan }\end{array}$ \\
\hline 1 & $\begin{array}{c}\text { Budaya } \\
\text { Kerja } \\
\left(\mathrm{X}_{1}\right)\end{array}$ & $\begin{array}{l}\text { Budaya kerja diartikan } \\
\text { sekumpulan konsep dasar atau } \\
\text { sebagai revolusi mental yang } \\
\text { berfungsi agar kerja lebih } \\
\text { efesien dan hubungan kerja } \\
\text { yang terjalin antar individu } \\
\text { yang berada dalam sekelompok } \\
\text { masyarakatNdraha (2005) }\end{array}$ & $\begin{array}{l}\text { a. Bersedia menerima } \\
\text { arahan atasan } \\
\text { b. Senang menerima } \\
\text { tanggungjawab kerja } \\
\text { c. Bekerja sebagai ibadah } \\
\text { d. Mengerjakan sesuai } \\
\text { tugasnya } \\
\text { e. Mengatasi kendala kerja } \\
\text { f. Membuat laporan kerja } \\
\text { g. Jujur dalam kerja } \\
\text { h. Kerjasama dengan } \\
\text { sesamanya } \\
\text { i. Mengevaluasi pekerjaan }\end{array}$ & Ordinal & $\begin{array}{c}1-3 \\
4-6 \\
7-8 \\
9-11 \\
12-13 \\
14-15 \\
16-18 \\
19-21 \\
22-23\end{array}$ \\
\hline 2 & $\begin{array}{l}\text { Iklim } \\
\text { Kerja } \\
\left(\mathrm{X}_{2}\right)\end{array}$ & $\begin{array}{l}\text { Iklim kerja merupakan mutu } \\
\text { lingkungan yang timbul dari } \\
\text { dalamperusahaan dan } \\
\text { berlangsung secara terus- } \\
\text { menerus, dialami oleh } \\
\text { karyawan perusahaan sehingga } \\
\text { mempengaruhi tingkah laku } \\
\text { karyawannya. .Wirawan (2007) }\end{array}$ & $\begin{array}{ll}\text { 1. Struktur } \\
\text { 2. Standar-standar } \\
\text { 3. Tanggung jawab } \\
\text { 4. Penghargaan } \\
\text { 5. Dukungan } \\
\text { 6. Komitmen }\end{array}$ & Ordinal & $\begin{array}{c}1-3 \\
4-6 \\
7-8 \\
9 \\
10-12 \\
13-14\end{array}$ \\
\hline 3 & $\begin{array}{c}\text { Disiplin } \\
\text { Kerja } \\
(Y)\end{array}$ & $\begin{array}{l}\text { Suatu pedoman para pimpinan } \\
\text { perusahaan untuk melakukan } \\
\text { komunikasi dengan karyawan } \\
\text { agar karyawan bersedia } \\
\text { merubah sikap dan berusaha } \\
\text { mampu menciptakan kesadaran } \\
\text { dari dalam dirinya sendiri untuk } \\
\text { mematuhi aturan perusahaan. } \\
\text { Rivai (2011) }\end{array}$ & $\begin{array}{l}\text { 1. } \text { patuh terhadap aturan } \\
\text { waktu } \\
\text { 2. patuh terhadap aturan } \\
\text { perusahaan } \\
\text { 3. patuh terhadap aturan } \\
\text { perilaku dalam pekerjaan } \\
\text { 4. patuh terhadap aturan } \\
\text { lainnya di perusahaan }\end{array}$ & Ordinal & $\begin{array}{c}1 \\
2-4 \\
5-6 \\
7-8\end{array}$ \\
\hline
\end{tabular}

\section{Sampel Penelitian}

Unit analisis pada tempat penelitian ialah seluruh PNS dengan jumlah 80 orang dengan sampel diambil dari keseluruhan PNS. Menurut Arikunto (2006), jika orang yang dijadikan sampel kurang dari seratus untuk pengambilan sampel, lebih baik untuk mengambil seluruh sampel tersebut maka sampel penelitian adalah populasinya. Sedangkan data primer ialah data yang didapatkan lewat jawaban objek penelitian melalui kuesioner yang disediakan, yaitu berupa data mengenai fenomena pendapat atau fenomena dari objek. Sedangkan data sekunder diperoleh melalui studi kepustakaan melalui membaca serta mempelajari literatur, buku, jurnal, skripsi, dari data internet dan data-data laporan perusahaan. Sedangkan untuk pengumpulan data yaitu: 1) Riset lapangan terdiri dari: kuesioner, wawancara, observasi; 2) Metode Riset Kepustakaan, 
dalam melakukan studi pustaka, penulis mengkaji teori yang bersangkutan dengan pemasalahan.

\section{Pengujian instrument}

Uji validitas dilakukan menguji tidak valid atau validnya kuesioner, adapun pengujian validitas yaitu jika dari hasil tersebut diperoleh $\mathrm{r}_{\text {hitung }} \geq \mathrm{r}$ tabel maka data valid yang berarti laya $\mathrm{k}$ digunakan, sedangkan $\mathrm{r}_{\text {hitung }}<\mathrm{r}$ tabel menunjukan bahwa data tidak valid yang artinya data itu tidak layak dengan kriteria $r_{\text {tabel }}$ yaitu 0,3 .

Berdasarkan uji validitas pada pernyataan variabel dari variabel $\mathrm{X}$ serta komitmen variabel $\mathrm{Y}$ menggambarkan instrument dikatakan valid karena nilai korelasi sesuai dengan nilai yang dipakai yaitu rhitung $\geq$ rtabel yang dijelaskan bahwa nilai-nilai itu lebih besar sama yaitu $(\geq 0,3)$. Sedangkan untuk mengukur koefisien keandalan (reability) kuesioner menggunakan cara Cronbach Alpha diuji pada alpha 0 (nol) - 1 (satu). Dengan kriteria pengujian reliabilitas adalah jika $r_{\text {hitung" }} \geq r_{\text {tabel }}$ yang berarti reliabel, serta sebaliknya jika $r_{\text {hitung }}<r_{\text {tabel }}$ yang artinya tidak reliabel. Suatu instrument dapat dinyatakan reliabel jika memiliki nilai alpha 0,6 atau lebih. Dengan hasil perhitungan yang menghasilkan bahwa variabel penelitian ini memenuhi uji reliabilitas dimana alpha $\geq 0,6$. Dengan demikian, maka semua variabel penelitian dinyatakan reliable karena didapatkan hasil $r_{\text {hitung }} \geq r_{\text {tabel }}$.

\section{Uji Asumsi Klasik}

\section{Uji Normalitas}

Berdasarkan uji ini memakai grafik P-Plot di mana gambar P-Plot yang dapat diartikan bahwa data terdistribusi normal sebab data menyebar dan mengikuti arah garis diagonal, jadi model regresi memenuhi normalitas dan model regresi telah memenuhi uji asumsi normalitas.

\section{Uji Multikolinearitas}

Batasan yang digunakan ialah nilai tolerance > 0,05 atau VIF < 5. Model regresi linier berganda baik adalah terbebas dari multikolinearitas sehinga dipakai pada penelitian.

\section{Uji Heterokedastisitas}

Pengujian ini bermaksud mengetahui sama atau perbedaan varian suatu residual antar pengamatan. Berdasarkan hasil penggujian heteroskedastisitas mengartikan tidak ada heteroskedastisitas pada model persamaan regresi, sehingga dinyatakan layak untuk digunakan dalam memprediksi disiplin kerja pegawai karena titik-titik pada sumbu $\mathrm{Y}$ dengan menyebar di atas dan di bawah angka 0 tanpa membentuk pola tertentu.

\section{Metode Analisis dan Langkah-Langkahnya}

Melalui skala Likert variabel diukur dijabarkan dengan memperhatikan tanggapan responden, deskripsi tersebut digunakan untuk menghitung scoring dan nilai rata-rata:

\section{Tabel 3 Skala Pengukuran Variabel}

\begin{tabular}{lc}
\hline \multicolumn{1}{c}{ Alternatif Jawaban } & Skor \\
\hline Sangat Setuju/Sangat Baik & 5 \\
Setuju/Baik & 4 \\
Cukup Setuju/Cukup Baik & 3 \\
Tidak Setuju/Tidak Baik & 2 \\
Sangat Tidak Setuju/Sangat Tidak Baik & 1 \\
\hline
\end{tabular}

Sumber: Sugiyono, 2013 
Untuk mengukur pengaruh antara suatu variabel terikat dengan dua atau lebih variabel bebas persamaan atau fungsi dalam regresi sebagai berikut:

$$
\boldsymbol{Y}=\boldsymbol{a}+\boldsymbol{\beta}_{1} \boldsymbol{X}_{1}+\boldsymbol{\beta}_{2} \boldsymbol{X}_{2}+\boldsymbol{e}
$$

Analisis korelasi berganda menurut Sugiyono (2013), menjelaskan kuatnya hubungan dari dua variabel atau lebih variabel independent secara bersama-sama terhadap satu variabel dependent. Dengan pedoman penafsiran dari korelasi besar kecilnya berikut:

\section{Tabel 4 Interpretasi Nilai $r$}

\begin{tabular}{cc}
\hline Interval Nilai $\mathbf{r}$ & Interpretasi \\
\hline $0,001-0,200$ & Sangat Lemah \\
$0,201-0,400$ & Lemah \\
$0,401-0,600$ & Cukup Kuat \\
$0,601-0,800$ & Kuat \\
$0,801-1,000$ & Sangat Kuat \\
\hline
\end{tabular}

Sumber: Sugiyono, 2013

Koefisien determinasi menurut Ghozali (2005), dapat digunakan dalam mengukur kemampuan dari sebuah model dalam menjelaskan variasi variabel terikat yang dengan menggunakan:

$$
\mathrm{KD}=\mathrm{r}^{2} \times 100 \%
$$

Uji $\mathrm{F}$ dilakukan untuk melihat pengaruh variabel bebas secara simultan terhadap variabel terikat dan untuk menguji signifikan hubungan variabel bebas dengan variabel terikat secara simultan. (Sugiyono, 2013). Dengan rumus Uji F sebagai berikut:

$$
F=\frac{R^{2} / K}{\left(1-R^{2}\right) /(n-K-1)}
$$

Untuk menguj pengaruh secara parsial digunakan uji $\mathrm{t}$ dengan asumsi tingkat signifikan $(\alpha)$ sebesar 0,05. Dengan tahap perumusan hipotesis, menentukan tingkat signifikansi $(\alpha)$, (dk) derajad kebebasan dengan rumus n-k-1. Menurut Sugiyono (2013), adapun rumus pada Uji t yaitu:

Tabel 5 Rekapitulasi Karakteristik Pegawai

\begin{tabular}{llccc}
\hline No & Jenis Karakteristik & Ciri-ciri Pegawai & $\begin{array}{c}\text { Jumlah } \\
\text { Pegawai }\end{array}$ & $\begin{array}{c}\text { Presentase } \\
(\mathbf{\%})\end{array}$ \\
\hline 1 & Jenis Kelamin & Laki-laki & 56 & 70 \\
2 & Usia & 20-30 Tahun & 32 & 40 \\
3 & Pendidikan Terakhir & Sarjana & 55 & 68,75 \\
4 & Pendapatan & Rp 2.400.000 - Rp & 75 & 93,75 \\
& & 5.000 .000 & & \\
\hline
\end{tabular}

Berdasarkan Tabel 5 di atas dapat dilihat Tahun, rata-rata berpendidikan sarjana dengan bahwa mayoritas karakteristik pegawai pendapatan Rp 2.400 .000 - Rp 5.000.000 per berjenis kelamin laki-laki dengan usia 20 - 30 bulan.

$$
t=\frac{r(n-2)}{\left(1-r^{2}\right)}
$$

Hasil dari pengujian hipotesis tersebut adalah:

a) Bila thitung lebih kecil dari atau sama dengan $\mathrm{t}_{\text {tabel }}\left(\mathrm{t}_{\text {hitung }} \leq \mathrm{t}_{\text {tabel }}\right)$ pada $\alpha=0,05$ maka Ho diterima dan Ha ditolak.

b) Bila $t_{\text {hitung }}$ lebih besar dari $t_{\text {tabel }}\left(t_{\text {hitung }}>t_{\text {tabel }}\right)$ pada $\alpha=0,05$ maka Ho ditolak dan $\mathrm{Ha}$ diterima.

\section{HASIL DAN PEMBAHASAN}

Kantor Pertanahan di Kota Bogor sendiri terletak di Jl. Ahmad Yani No. 41, Kecamatan Tanah Sareal, Kota Bogor.

\section{Deskripsi Pegawai}

Deskripsi pegawai Kantor Pertanahan berdasarkan karakteristik pegawai berikut ini: 
Tabel 6 Rekapitulasi Tanggapan Responden Terhadap Budaya Kerja

\begin{tabular}{|c|c|c|c|}
\hline No & Pernyataan & Jawaban & Kriteria \\
\hline 1 & Pegawai bersedia menerima arahan pimpinan sebelum memulai pekerjaan & 4,30 & Sangat Kuat \\
\hline 2 & $\begin{array}{l}\text { Ketika pekerjaan berlangsung pegawai mengikuti arahan yang telah } \\
\text { diberikan pimpinan }\end{array}$ & 3,65 & Kuat \\
\hline 3 & $\begin{array}{l}\text { Pegawai membuat laporan akhir sesuai dengan arahan yang diberikan } \\
\text { pimpinan }\end{array}$ & 3,49 & Kuat \\
\hline 4 & Pegawai senang menerima tanggungjawab kerja & 4,03 & Kuat \\
\hline 5 & Tanggungjawab pekerjaan adalah kewajiban bukan hak & 4,03 & Kuat \\
\hline 6 & $\begin{array}{l}\text { Pegawai benar-benar merasakan kepuasan dalam bekerja melebihi } \\
\text { kegiatan lainnya }\end{array}$ & 3,26 & Cukup Kuat \\
\hline 7 & Pegawai melaksanakan pekerjan dengan ikhlas & 4,23 & Sangat Kuat \\
\hline 8 & Pegawai melaksanakan pekerjaan sebagai bagian dari ibadah & 4,33 & Sangat Kuat \\
\hline 9 & Melaksanakan pekerjaan sesuai tugas yang diberikan & 4,23 & Sangat Kuat \\
\hline 10 & Tidak mengerjakan pekerjaan orang lain & 3,15 & Kuat \\
\hline 11 & Mengerti dengan pekerjaan yang harus dikerjakan & 4,12 & Kuat \\
\hline 12 & Pegawai harus bisa mengatasi kendala kerja & 3,37 & Cukup Kuat \\
\hline 13 & Pegawai selalu merundingkan permasalahan kerja dengan rekan kerja & 3,70 & Kuat \\
\hline 14 & Pegawai harus bisa menyusun laporan kerja & 4,15 & Kuat \\
\hline 15 & Penyusunan laporan kerja harus rapi dan benar & 4,82 & Sangat Kuat \\
\hline 16 & Mengerjakan pekerjaan dengan standar baik & 4,11 & Kuat \\
\hline 17 & Tidak absen terlalu lama dari pekerjaan & 4,72 & Sangat Kuat \\
\hline 18 & $\begin{array}{l}\text { Tidak menghabiskan banyak waktu bermain dengan telepon genggam } \\
\text { pribadi }\end{array}$ & 4,13 & Kuat \\
\hline 19 & Membina hubungan yang baik terhadap seluruh pegawai & 4,28 & Sangat Kuat \\
\hline 20 & Komunikasi baik dengan sesama rekan kerja & 4,22 & Sangat Kuat \\
\hline 21 & $\begin{array}{l}\text { Pegawai akan membantu sesama rekan kerja saat mereka memerlukan } \\
\text { bantuan saat bekerja }\end{array}$ & 4,06 & Kuat \\
\hline 22 & Pegawai harus bisa mengetahui kekurangan dan kelebihan dalam bekerja & 4,05 & Kuat \\
\hline \multirow[t]{2}{*}{23} & Pegawai lebih suka bekerja dibanding kegiatan lainnya & 3,83 & Kuat \\
\hline & Nilai Rata-rata & $\mathbf{4 , 0 2}$ & Kuat \\
\hline
\end{tabular}

Berdasarkan Tabel 6 tersebut, nilai rata-rata bahwa dalam bekerja harus mengetahui tanggapan responden untuk variabel budaya kekurangan dan kelebihannya, serta pegawai kerja yaitu sebesar 4,02 yang termasuk dalam memahami bahwa melaksanakan pekerjaan kategori kuat. Artinya hampir seluruh pegawai harus sesuai uraian pekerjaan yang telah memahami dan melaksanakan arahan diberikan. Hal tersebut menunjukan bahwa pimpinan, memahami bahwa melaksanakan variabel budaya kerja memiliki pengaruh tanggungjawab adalah kewajiban, memahami terhadap disiplin kerja pegawai.

Tabel 7 Rekapitulasi Tanggapan Responden Terhadap Iklim Kerja

\begin{tabular}{llcc}
\hline No & \multicolumn{1}{c}{ Pernyataan } & Jawaban & Kriteria \\
\hline 1 & Kejelasan tujuan instansi & 4,21 & Sangat Baik \\
2 & Kejelasan visi dan misi instansi & 4,21 & Sangat Baik \\
3 & Kejelasan tanggungjawab dan wewenang pegawai & 4,33 & Sangat Baik \\
4 & Standar kerja yang diterapkan mendukung pencapaian tujuan kerja & 4,03 & Baik \\
5 & Hasil kerja/output sesuai dengan standar kerja yang ada & 4,05 & Baik \\
6 & Evaluasi hasil kerja dibandingkan dengan standar kerja yang sudah ada & 4,07 & Baik \\
7 & Tanggungjawab dalam pengambilan keputusan & 4,17 & Baik \\
8 & Tanggungjawab dalam penyelesaian masalah & 4,11 & Baik \\
9 & Pemberian imbalan sesuai dengan profesi kerja & 4,05 & Baik \\
10 & Hubungan dengan rekan kerja dan atasan berjalan dengan harmonis & 4,02 & Baik \\
11 & Adanya dukungan dan bantuan sejawat dalam menyelesaikan masalah & 3,81 & Baik \\
12 & Komunikasi dengan rekan kerja dan pimpinan berjalan efektif & 3,80 & Baik \\
\hline
\end{tabular}




\begin{tabular}{lllllll}
\hline 13 & Kesetiaan pada instansi/perusahaan & & & 4,17 & & Baik \\
14 & Mampu mengerahkan seluruh tenaganya demi & tujuan & 4,15 & Baik \\
& perusahaan/instansi
\end{tabular}

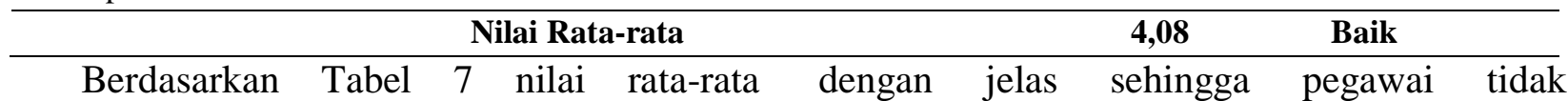
tanggapan responden untuk indikator variabel mengalami kendala dalam melaksanakan iklim kerja yaitu sebesar 4,08. Kondisi sebesar pekerjaan. Hal tersebut menunjukkan bahwa 4,08 memberikan penjelasan bahwa struktur, iklim kerja berpengaruh terhadap disiplin kerja standar-standar, tanggungjawab, dukungan, pegawai . serta komitmen pegawai sudah dirumuskan

Tabel 8 Rekapitulasi Tanggapan Responden Terhadap Disiplin Kerja

\begin{tabular}{llcc}
\hline No & \multicolumn{1}{c}{ Pernyataan } & Jawaban & Kriteria \\
\hline 1 & Datang bekerja tepat waktu & 3,76 & Tinggi \\
2 & Berpakaian rapi sesuai aturan yang berlaku & 4,07 & Tinggi \\
3 & Bertingkah laku sopan sesama rekan kerja maupun atasan & 4,00 & Tinggi \\
4 & Memelihara dan menjaga kelengkapan kerja & 3,46 & Tinggi \\
5 & Menjaga lingkungan kerja & 4,11 & Tinggi \\
6 & Merawat fasilitas pekerjaan & 3,37 & Cukup Tinggi \\
7 & Menjalankan tugas-tugas kerja sesuai mekanisme kerja & 3,55 & Tinggi \\
8 & Mematuhi instruksi atasan/pimpinan & 3,53 & Tinggi \\
\hline & Nilai Rata-rata & $\mathbf{3 , 7 3}$ & Tinggi \\
\hline
\end{tabular}

Berdasarkan tabel 8 tersebut nilai rata-rata tanggapan responden untuk variabel disiplin kerja yaitu sebesar 3,73. Kondisi sebesar 3,73 memberikan penjelasan bahwa pegawai memahami peraturan dan harus dilaksanakan dengan benar. Hal tersebut menunjukan bahwa disiplin kerja pegawai dipengaruhi oleh variabel budaya kerja dan iklim kerja. mematuhi disiplin kerja dengan berkontribusi

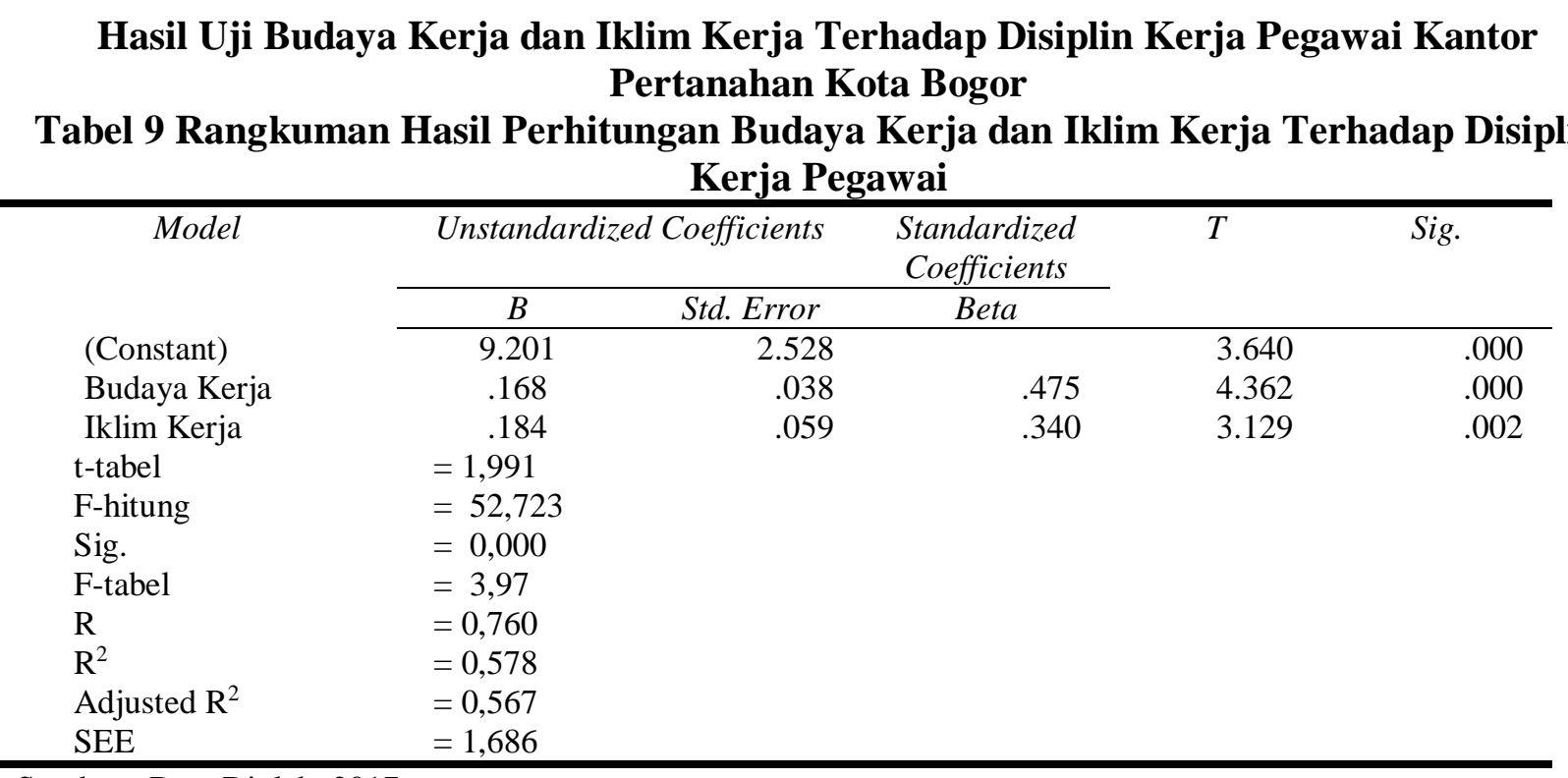

Sumber : Data Diolah, 2017

Berdasarkan Tabel 9 menggunakan sebesar 57,8 \% dari variabel dependent. Secara regresi berganda bahwa dapat dijelaskan keseluruhan ini signifikan pada tingkat 
kepercayaan 95\%. (F-hitung 52,723) sehingga model ini cukup memadai untuk digunakan sebagai alat analisis. Secara parsial budaya kerja dan iklim kerja berpengaruh terhadap disiplin kerja pegawai. Hal ini sejalan dengan penelitian Oktaviani (20017) yang menyebutkan bahwa budaya organisasi berpengaruh secara positif dan signifikan terhadap disiplin kerja karyawan Kantor Pusat PT Kereta Api Indonesia (PERSERO) dan penelitian Tarigan (2016) bahwa terdapat pengaruh yang kuat dan signifikan antara iklim organisasi dan komitmen organisasi terhadap kedisiplinan kerja.

\section{SIMPULAN DAN IMPLIKASI}

Berdasarkan penelitian yang dilakukan, maka didapatkan beberapa kesimpulan sebagai berikut: (1) Kondisi budaya kerja secara ratarata berada pada kategori kuat, iklim kerja secara rata-rata berada pada kategori baik, dan disiplin kerja pegawai secara rata-rata berada pada kategori tinggi. (2) Budaya kerja dan iklim kerja secara simultan mempunyai pengaruh positif dan signifikan terhadap disiplin kerja pegawai. (3) Budaya kerja mempunyai pengaruh positif dan signifikan terhadap disiplin kerja pegawai. (4) Iklim kerja mempunyai pengaruh positif dan signifikan terhadap disiplin kerja pegawai.

Berdasarkan hasil penelitian, ada beberapa saran yang penulis kemukakan mengenai budaya kerja dan iklim kerja terhadap disiplin kerja pegawai, yang diuraikan sebagai berikut: (1) Untuk budaya kerja sebaiknya perusahaan lebih meningkatkan kepuasan dalam bekerja dibanding kegiatan lainnya dengan cara menempatkan pegawai pada posisi yang tepat, berat ringannya pekerjaan sesuai kemampuan, suasana dan lingkungan pekerjaan yang mendukung, serta sarana dan prasarana yang menunjang sehingga pegawai merasa puas dalam bekerja. (2) Untuk iklim kerja sebaiknya perusahaan terus meningkatkan komunikasi yang terjalin antar semua pihak baik itu sesama rekan kerja ataupun atasan agar kondisi kerja ataupun iklim kerja berjalan kondusif. Penciptaan iklim kerja yang kondusif perlu dilakukan mengingat penyelesaian tugas pekerjaan memerlukan dukungan dari lingkungan yang ada di sekitar sehingga pegawai akan mampu menyelesaikan tugasnya dengan baik. (3) Untuk disiplin kerja sebaiknya perusahaan lebih meningkatkan pegawai ikut berkontribusi dalam membantu merawat fasilitas kerja sehingga membuat sarana dan prasarana yang ada di instansi akan tetap terjaga, serta lebih meningkatkan pelaksanaan disiplin kerja pegawai, dengan pemberian sanksi yang tegas apabila terdapat pegawai yang melanggar peraturan yang telah dibuat perusahaan/instansi. (4) Untuk penelitian lanjutan dapat ditambahkan variabel lain yang dapat mempengaruhi disiplin kerja pegawai selain budaya kerja dan iklim kerja diantaranya kompensasi, gaya kepemimpinan, lingkungan kerja dan lain sebagainya agar nilai presentase pengaruh terhadap disiplin kerja lebih tinggi.

\section{UCAPAN TERIMA KASIH}

Ucapan terima kasih kepada Kantor Pertanahan Kota Bogor yang telah memberikan ijin kepada penulis untuk melakukan penelitian diperusahaannya.

\section{DAFTAR PUSTAKA}

Amar, Syamsul. 2014. Pengaruh Kepemimpinan Kepala Sekolah, Iklim Kerja, dan Motivasi Berprestasi Terhadap Disiplin Kerja Guru SMP Negeri 18 Padang. Jurnal Riset 
Manajemen Bisnis dan Publik. Ejournal.unp.ac.id Vol. 2, No. 2, 2014, ISSN : $2337-5345$

Arikunto, Suharsini. 2006. Prosedur Penelitian Suatu Pendekatan Teknik. Jakarta..PT Rineka Cipta.

Artina, H.B Isyandi, Sri Indarti. 2013. Pengaruh Kepemimpinan, Budaya Kerja, Lingkungan Kerja Terhadap Disiplin Kerja dan Kinerja Personil POLDA RIAU. Jurnal Tepak Manajemen Bisnis. Vol. VI No. 2 Mei 2014.

B. Siswanto. 2012, Manajemen Tenaga Kerja Indonesia Pendekatan Administrasi dan Operasional. Jakarta. PT Bumi Aksara.

Cahyantara, I Putu., dan Made Subudi. 2013. Pengaruh Gaya Kepemimpinan Partisipatif dan Budaya Kerja Terhadap Disipilin Kerja Karyawan dan Produktivitas Kerja Karyawan pada PT. PLN (Persero) Distribusi Bali, Area Bali Selatan. E-Jurnal Manajemen Unud, Vol. 4, No. 7, 2015: 2016-2035, ISSN: 2302-8912

Erawati. 2007. Pengaruh Budaya Organisasi, Kepemimpinan dan Kompensasi terhadap Disiplin Kerja Pegawai Sekretariat Daerah Kabupaten Kotabaru Kalimantan Selatan. Tesis. Universitas Airlangga.

Fernandez, R. 2006. Women, Work, and Culture. CEPR dan NBER. halaman 138.

Ghozali, Imam. 2005. Aplikasi Analisis Multivariate Dengan Program SPSS. Semarang. Badan Penerbit Universitas Diponegoro.

Kusdi. 2011. Budaya Organisasi Teori, Penelitian, dan Praktik. Jakarta. Salemba Empat.

Mills, Martin., Goos Merrylin. 2007. Productive Pedagogies: Working with Disciplines and Teacher and Student Voices. Paper Presented at the annual conference of the Australian
Association for Research in Education, Fremantle.

Nazir, Muhammad. 2003. Metode Penelitian. Jakarta. Cetakan Kelima. Indonesia. Ghalia.

Ndraha, Taliziduhu. 2005. Teori Budaya Organisasi. Jakarta. Cet.Pertama. PT Rineka Cipta.

Oktaviani, Dwi Widya dan Romat Saragih. 2017. Pengaruh Budaya Organasisi Terhadap Disiplin Karyawan Kantor Pusat PT KERETA API INDONESIA (PERSERO). Jurnal e-Proceeding of Management:Vol.4, No 1 April 2017 Page : 687, ISSN : 2255-9357.

Sugiyono. 2013. Metode Penelitian Kuantitatif, Kualitatif, Kombinasi (Mixed Methods). Bandung. Alfabeta.

Supriyadi, Gering. Dan Guno, Tri. 2006. Budaya Kerja Organisasi Pemerintah: Modul Pendidikan dan Pelatihan Prajabatan Golongan III. Jakarta. Lembaga Administrasi Negara.

Tarigan, Kawas Gabriel. 2016. Pengaruh Iklim Organisasi dan Komitmen Karyawan Terhadap Kedisiplinan Karyawan Pada Perusahaan Daerah Air Minum Tirta Kencana SAMARINDA. eJournal Psikologi, ejournal.psikologi.fisipunmul.ac.id. Vol : 4(4) :472-480, ISSN 2477-2674.

Veithzal, Rivai. 2011. Kepemimpinan dan Perilaku Organisasi. Jakarta. PT Raja Grafindo Persada.

Wirawan. 2007. Budaya dan Iklim Organisasi: Teori Aplikasi dan Penelitian. Jakarta. Salemba Empat. 